\title{
Seismic Vulnerability Evaluation of a Three-Span Continuous Beam Railway Bridge
}

\author{
Chongwen Jiang, ${ }^{1}$ Biao Wei, ${ }^{2}$ Dianbin Wang, ${ }^{3}$ Lizhong Jiang, ${ }^{2}$ and Xuhui He ${ }^{2}$ \\ ${ }^{1}$ School of Civil Engineering, Hunan University, Changsha 410000, China \\ ${ }^{2}$ School of Civil Engineering, Central South University, Changsha 410075, China \\ ${ }^{3}$ China Railway Eryuan Engineering Group Co. Ltd, Chengdu 610000, China \\ Correspondence should be addressed to Biao Wei; weibiao@csu.edu.cn
}

Received 18 May 2017; Accepted 7 September 2017; Published 18 October 2017

Academic Editor: Michele Betti

Copyright (C) 2017 Chongwen Jiang et al. This is an open access article distributed under the Creative Commons Attribution License, which permits unrestricted use, distribution, and reproduction in any medium, provided the original work is properly cited.

\begin{abstract}
In order to evaluate the seismic vulnerability of a railway bridge, a nonlinear finite element model of typical three-span continuous beam bridge on the Sichuan-Tibet railway in China was built. It further aimed at performing a probabilistic seismic demand analysis based on the seismic performance of the above-mentioned bridge. Firstly, the uncertainties of bridge parameters were analyzed while a set of finite element model samples were formulated with Latin hypercube sampling method. Secondly, under Wenchuan earthquake ground motions, an incremental dynamic method (IDA) analysis was performed, and the seismic peak responses of bridge components were recorded. Thirdly, the probabilistic seismic demand model for the bridge principal components under the prerequisite of two different kinds of bearing, with and without seismic isolation, was generated. Finally, comparison was drawn to further ascertain the effect of two different kinds of bearings on the fragility components. Based on the reliability theory, results were presented concerning the seismic fragility curves.
\end{abstract}

\section{Introduction}

In recent years, with the rapid development of China's western railway network, a large number of railway lines have emerged in the western regions. With a full length of $1,629 \mathrm{~km}$, Sichuan-Tibet railway is currently under construction. To span across topographically complex regions with high mountains and deep valleys, three-span continuous beam railway bridge structure has been widely employed. Due to topographical reasons, these bridges are often provided with long span and large height. Besides, there is also very large interpier height difference, with some reaching up to 20-30 meters. For such irregular continuous beam bridges, ever-increasing pier height and span have brought about many technological problems to seismic design. In addition, there have been frequent seismic activities in the western regions in recent years, such as 2008 Wenchuan earthquake (M8.0), 2010 Yushu earthquake (M7.1), and 2013 Lushan earthquake (M7.0). These factors would seriously challenge the seismic safety of typical three-span continuous beam bridges on the Sichuan-Tibet railway.

With the development of seismic theories for bridge structures, seismic vulnerability analysis has become an important approach to evaluate the seismic behavior of bridge structures [1]. Seismic vulnerability refers to the conditional probability that seismic damage of a structure or component exceeds respective seismic capacity. At present, three types of fragility curves are mainly analyzed, namely, analytical fragility curves, empirical fragility curves, and expert opinion fragility curves [2]. In reality, there has been lack of seismic disaster data on bridge structures in many regions, due to which scholars have made more extensive and in-depth researches on the creation of analytical seismic fragility curves. In recent years, scholars have carried out a series of studies on typical bridges with the seismic vulnerability theory. Moreover, based on the reliability theory, Hwang et al. [3] analyzed the seismic vulnerability of typical three-span continuous beam highway bridge in east-central United States 
while Nielson and DesRoches [4] carried out vulnerability analysis on the components and systems of typical simply supported beam bridges in central and southeastern United States. Gianmarco and Giannini [5] analyzed the seismic fragility of multispan simply supported beam bridge based on the response surface methodology taking into account the uncertainties of structural parameters. Besides, Choi [6] et al. carried out seismic vulnerability analysis on four typical types of beam bridges in south-central United States, in which the influence of different components on the bridge system vulnerability was taken into consideration. Wang [7] made vertical and horizontal seismic fragility analyses on typical $32 \mathrm{~m}$ simply supported beam railway bridges in China, so as to further study the effects of ordinary bearings and seismic isolated ones on vulnerability. Zhou and Wang [8] analyzed the seismic vulnerability of common double$\mathrm{T}$ small-span continuous bridges in China for evaluating the seismic performance of such bridges, while a seismic vulnerability analysis was also conducted by Feng [9] on piers and bearings of a continuous beam highway bridge. In addition, through the use of numerical simulation, Zhang [10] analyzed the seismic vulnerability of three-span continuous beam highway bridge. However, the above studies mainly focused on highway or railway simply supported beam bridges or small-span continuous beam highway bridges with low piers, while little attention has been paid to the seismic vulnerability of common high-pier, large-span continuous beam railway bridges. When it comes to the effects of different bearing types on the seismic vulnerability of continuous beam bridges, relevant studies have been seldom presented. Therefore, there is an urgent need for the research on the seismic vulnerability of typical three-span continuous beam railway bridges.

This paper studies a three-span continuous beam bridge $(40 m+64 m+40 m)$ on the Sichuan-Tibet railway that is under construction. Firstly, a 3D finite element model of this typical bridge was built, followed by the creation of ground motion-bridge analysis sample database considering the uncertainties of bridge model parameters and ground motions. And then a dynamic nonlinear time-history analysis was performed on the sample database, based on which a probabilistic seismic demand model for the bridge principal components was also constructed. Finally, the seismic fragility curves for dangerous components of the bridge were generated, and the seismic behavior was evaluated, along with the comparison made about the effects of two different bearing types on bridge structure vulnerability.

\section{Seismic Vulnerability Analysis Theories}

2.1. Probabilistic Seismic Demand Model. The main purpose of probabilistic seismic demand models was to establish the relationship between ground motion intensity and structural seismic demand for a certain type of structure. Based on the seismic demand followed by lognormal distribution, Cornell et al. [11] recommended that the logarithmic medians of demand $\ln \widehat{D}$ and ground motion intensity $\ln (\mathrm{IM})$ shall obey a linear relation of bridge structure and the ground motion intensity as follows:

$$
\ln \widehat{D}=A \times \ln (\mathrm{IM})+B+\zeta \times Z,
$$

where $Z \sim N(0,1)$ is standard normal random variable; $\zeta$ refers to the conditional logarithmic standard deviation of bridge structure seismic demand; and parameters $A$ and $B$ could be solved by the least square method. Linear regression was widely used in vulnerability analysis $[12,13]$. However, the premise for the adoption of the method can be described as follows: ground motion intensity IM and median seismic displacement demand $\widehat{D}$ follow a linear relation in logarithmic space. Under the action of the $i$ th ground motion, the residual between actual seismic demand $\ln D_{i}$ of piers and predicted value by demand model (1) was

$$
e_{i}=\ln D_{i}-A \times \ln \left(\mathrm{IM}_{i}\right)-B .
$$

Then, the parameter $\zeta$ in (1) was

$$
\zeta^{2}=\sum_{i=1}^{N} \frac{e_{i}^{2}}{(N-2)} .
$$

2.2. Seismic Vulnerability of Bridge Components. Seismic vulnerability refers to the conditional probability that a structural component reaches or exceeds a particular damage state under a given ground motion. In terms of the conditional probability that seismic demand of bridge component is greater than the seismic capacity, it was shown in the following equation:

$$
P_{f}=P[D \geq C \mid \mathrm{IM}],
$$

where $P_{f}$ refers to the conditional probability to exceed a particular damage state. When the seismic demand $D$ and seismic capacity $C$ of bridge component obeyed lognormal distribution, the probability for the bridge component to reach or exceed a particular damage state shall also obey the lognormal distribution. Thus, based on the lognormal cumulative probability density function, bridge component vulnerability function (Kennedy and Ravindra [14]) could be obtained as follows:

$$
\begin{aligned}
P_{f} & =P[D \geq C \mid \mathrm{IM}]=\Phi\left[\frac{\ln (\widehat{D} / \widehat{C})}{\sqrt{\zeta^{2}+\beta_{c}^{2}}}\right] \\
& =1-\Phi\left[\frac{\ln (\widehat{C})-\ln (\widehat{D})}{\sqrt{\zeta^{2}+\beta_{c}^{2}}}\right],
\end{aligned}
$$

where $\widehat{C}$ indicates the median seismic capacity of bridge component; and $\beta_{c}$ is the logarithmic standard deviation of seismic capacity of bridge component. According to literature [1], $\beta_{c}=\sqrt{\ln \left(1+\mathrm{COV}^{2}\right)}$, where $\mathrm{COV}$ means the coefficient of variation. $\Phi[\cdot]$ represents the standard normal distribution function. And other parameters have been 


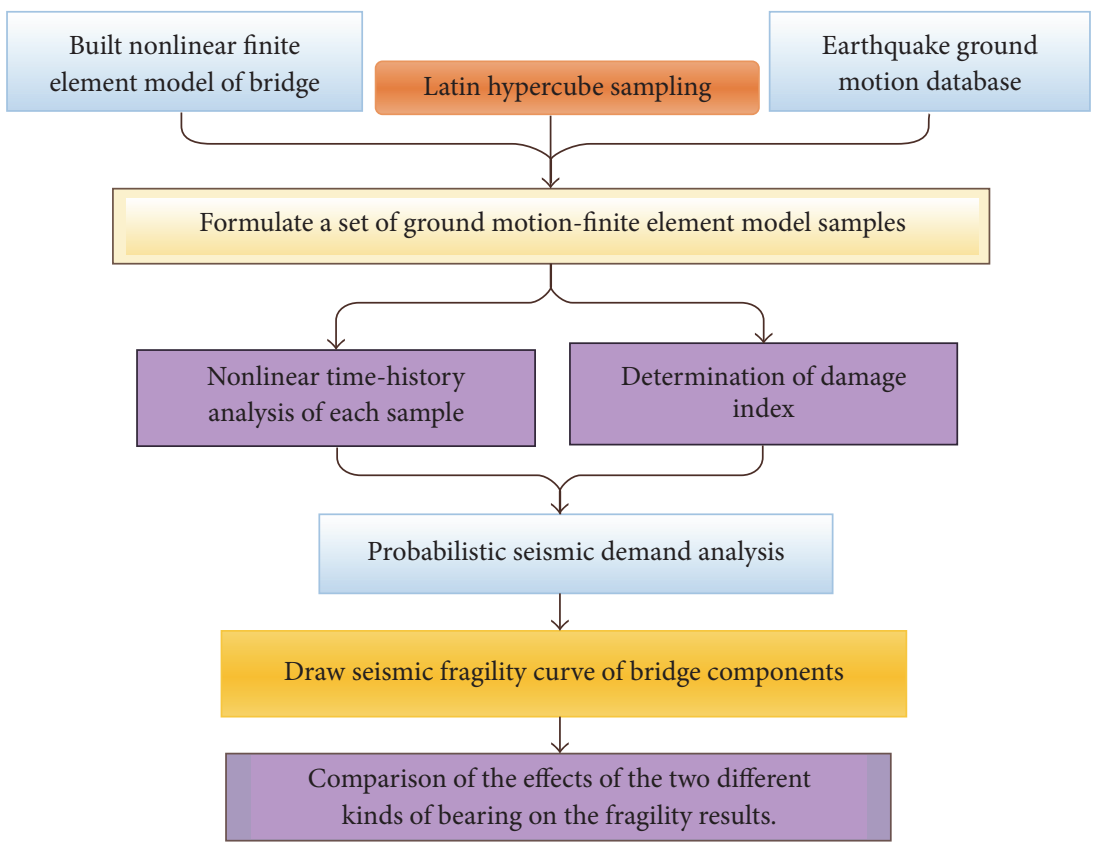

FIGURE 1: Flowchart of seismic vulnerability evaluation.
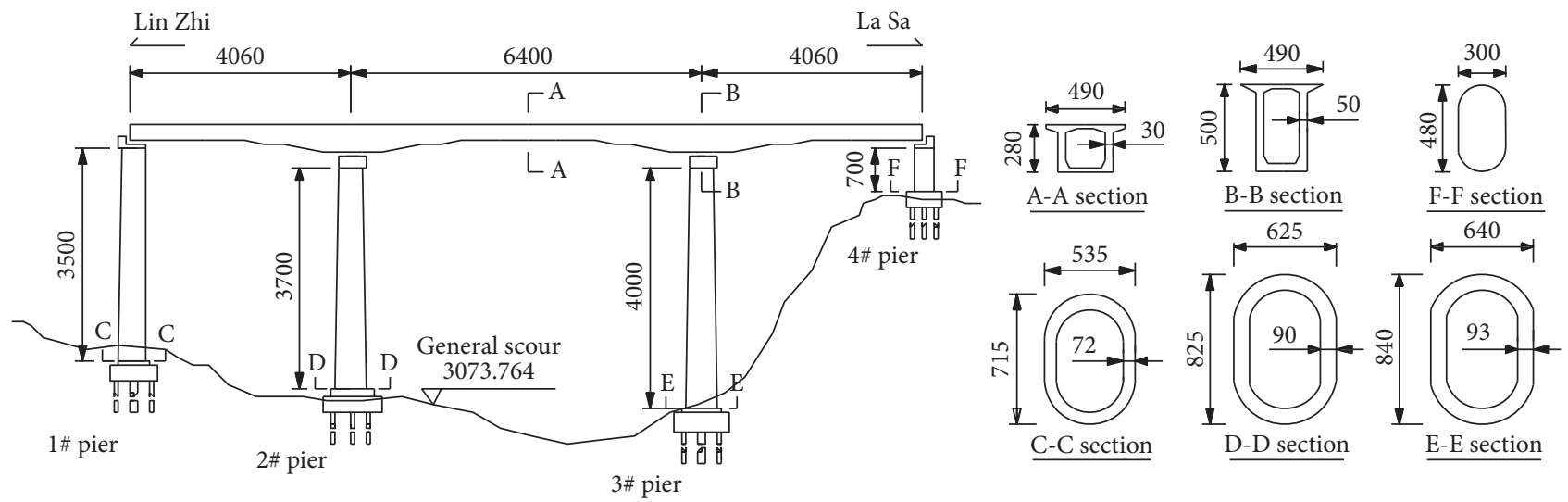

FIGURE 2: Three-span continuous beam bridge.

defined in (1), (2), and (3). Demand model (1) of bridge structure can be substituted into (5), thus getting

$$
P[D \geq C \mid \mathrm{IM}]=\Phi\left[\frac{\ln (\mathrm{IM})-\ln \alpha}{\beta}\right],
$$

where $\alpha$ and $\beta$ mean the median and logarithmic standard deviation of the bridge component vulnerability function, respectively. $\alpha=\exp [(\ln \widehat{C}-B) / A], \beta=\sqrt{\zeta^{2}+\beta_{c}^{2}} / A$.

Based on the above vulnerability analysis theories, seismic fragility analysis on three-span continuous beam railway bridges could thus be implemented.

2.3. Flow for Vulnerability Analysis. To perform seismic vulnerability analysis on typical three-span continuous beam railway bridge, a flowchart for seismic vulnerability evaluation was presented based on the above analysis theories (see Figure 1).

\section{Case Study of a Bridge}

3.1. Project Overview. With the Brahmaputra River Bridge under construction in Lang County on the Sichuan-Tibet railway taken as an example, seismic vulnerability of typical continuous beam railway bridge was discussed based on the analytical flow in Figure 1. The superstructure of bridge was three-span variable cross-section continuous box beams with span arrangement of $40 m+64 m+40 m$ and material of C55 concrete. Piers were round-ended hollow piers made of C35 concrete. Heights of piers 1 4\# were 35, 37, 40, and $7 \mathrm{~m}$, respectively (Figure 2), of which pier $2 \#$ was braking pier. Moreover, those piers had a longitudinal reinforcement ratio 
TABLE 1: The parameters of bearings.

\begin{tabular}{lcc}
\hline Pier number & Spherical steel bearing model & Seismic isolated bearing model \\
\hline $1 \#, 4 \#$ & LQZ3000DX-e150 & KZQZ-L-3000ZX \\
$2 \#$ & LQZ12500GD & KZQZ-L-12500GD \\
$3 \#$ & LQZ12500DX-e150 & KZQZ-L-12500ZX \\
\hline
\end{tabular}

of $1.36 \%$ and a stirrup reinforcement ratio of $0.85 \%$, while both the longitudinal bars and stirrups used grade HRB335 steel. This paper studied the vulnerability of bridge structure under two different bearing types, which are detailed in Table 1. For spherical steel bearings, the design horizontal force of longitudinal expansion bearings accounted for $5 \%$ of the design vertical bearing capacity, while the design horizontal force of fixed bearings occupied a percentage of $30 \%$ of the design vertical bearing capacity. In terms of the hyperboloid spherical seismic isolated bearings (hereinafter referred to as the seismic isolated bearings), the design horizontal forces of both longitudinal expansion and fixed bearings accounted for $20 \%$ of the design vertical bearing capacity.

3.2. Finite Element Model. In recent years, numerical analysis approaches have played a crucial role in the seismic analysis of structures. Among the analysis approaches mentioned above, the Open System for Earthquake Engineering Simulation (OpenSEES) developed by the US Pacific Earthquake Engineering Research Center has gradually gained widespread application. In this paper, OpenSEES was also used to perform nonlinear time-history analysis about the three-span continuous beam bridge.

An existing study on earthquake damage data has shown that, for most bridge structures, main beams were in substantially linear elastic state under seismic action [15]. In the present study, the main beams of finite element model were simulated with elastic beam elements, with self-weight and secondary dead loads taken into consideration. As piers were prone to damage and failure during earthquakes, force beam column elements based on flexibility method were thus employed for the simulation [16]. Moreover, elemental nonlinearity in the model was mainly reflected in the nonlinear stress-strain relation of fiber materials. Unconstrained and constrained concrete materials were defined with Kent-Scott-Park model [17] (Concrete02 material) in OpenSEES, while reinforcement materials were defined with Giuffre-Menegotto-Pinto model [18] (Steel02 material). For simulation of bearings, bilinear ideal elastoplastic spring elements were used based on the method in literature [19]. This paper intended to investigate the effects of spherical steel bearings and seismic isolated bearings on the seismic vulnerability of components, for which the definition of preyield and postyield stiffness of two types of bearings was required according to their specific design parameters [20] (Table 1). Specific parameter defining method is detailed in the literature [1]. Pile foundation was simulated with equivalent boundary elements. That is, pile group effect was equivalently simulated using six springs at the bottom of bearing platform. In terms of the stiffness of the six springs, it consists of vertical stiffness, axial and transverse direction

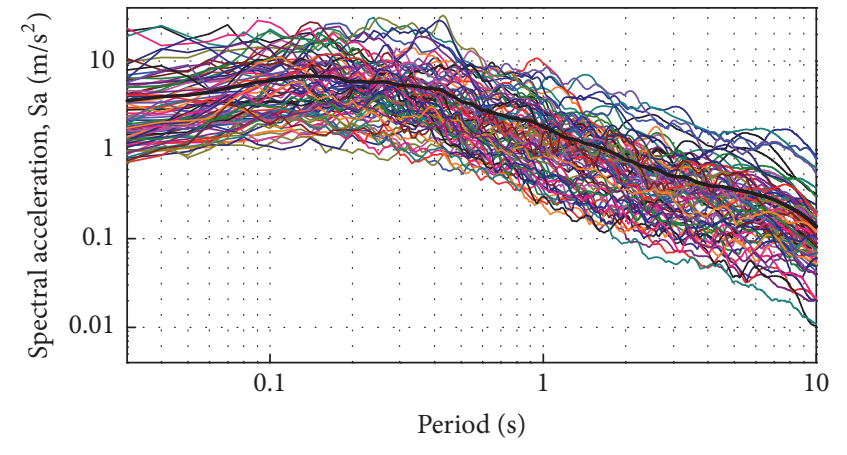

- Mean value

FIGURE 3: Characteristic graph of FFT spectra of acceleration response.

lateral stiffness, torsional stiffness around vertical axis, and two types of horizontal direction flexural stiffness. Equivalent stiffness of each pile foundation could be solved according to Appendix D, "computation theory of elastic resistance of pier and abutment foundations considering soil," under Specifications for Design of Railway Bridge and Culvert Foundations (TB 10002.5-2005), in [21].

\subsection{Uncertainties of Model Parameters}

3.3.1. Selection of Ground Motions. Given that the bridge studied herein was a typical three-span continuous beam bridge on the Sichuan-Tibet railway, actually measured data of ground motions in the region should be selected as far as possible. In this way, the seismic vulnerability analysis results of bridge were closer to the engineering practice. Thus, the actual ground motion data of Wenchuan earthquake was selected to perform the seismic vulnerability analysis. When Wenchuan earthquake occurred in 2008, over 400 stations in the China Digital Strong Motion Network received the data about ground motion, including 46 observation stations within Sichuan with recorded PGA of ground motions greater than $0.1 \mathrm{~g}$. After the comprehensive consideration of the intensity of ground motions, integrity of seismic records, and the spectral characteristics of near-field ground motions, 90 ground motion records from 30 observation stations were selected as the original inputs for the nonlinear dynamic analysis of the bridge studied. Table 2 lists the names of the 30 stations and peak ground acceleration, while Figure 3 illustrates the acceleration response spectra of various ground motions and their mean spectrum.

3.3.2. Uncertainties of Bridge Structure Parameters. For railway bridge structures, due to the effects of various factors 
TABLE 2: The seismological observation stations and PGA (peak ground acceleration) in three directions.

\begin{tabular}{|c|c|c|c|c|}
\hline Number & Seismological station & $\mathrm{EW}\left(\mathrm{cm} / \mathrm{s}^{2}\right)$ & $\mathrm{NS}\left(\mathrm{cm} / \mathrm{s}^{2}\right)$ & $\mathrm{UD}\left(\mathrm{cm} / \mathrm{s}^{2}\right)$ \\
\hline (1) & Tashui, An County & 289.5 & 203.45 & 179.93 \\
\hline (2) & Yanjing, Baoxing & 190.23 & 155.70 & 93.70 \\
\hline (3) & Hanzeng, Jiangyou & 519.49 & 350.14 & 444.33 \\
\hline (4) & Central District, Guangyuan & 320.49 & 273.97 & 143.70 \\
\hline (5) & Mao County & 306.57 & 302.16 & 266.64 \\
\hline (6) & Jiangyou seismological station & 511.33 & 458.68 & 198.28 \\
\hline (7) & Chonghua, Jiangyou & 297.19 & 278.96 & 180.49 \\
\hline (8) & Yongfeng, Jiuzhaigou & 91.74 & 100.04 & 65.31 \\
\hline (9) & Shaba, Li County & 221.26 & 261.76 & 211.09 \\
\hline (10) & Lushang Family Planning Bureau & 118.15 & 112.16 & 59.92 \\
\hline (11) & Minzhi, Baoxing & 153.25 & 117.09 & 109.24 \\
\hline (12) & Cangxi Weather Bureau & 184.83 & 166.93 & 69.86 \\
\hline (13) & Zengjia, Guangyuan & 424.48 & 410.48 & 183.34 \\
\hline (14) & Muka, Li County & 320.94 & 283.84 & 357.81 \\
\hline (15) & Taoping, Li County & 339.73 & 324.38 & 379.58 \\
\hline (16) & Feixianguan, Lushan & 124.14 & 94.03 & 47.66 \\
\hline (17) & Detuo, Luding & 109.42 & 112.07 & 56.02 \\
\hline (18) & Wudu, Jiangyou & 421.28 & 349.24 & 352.48 \\
\hline (19) & Mingshan Technology Bureau & 171.16 & 175.37 & 46.69 \\
\hline (20) & Wuxing, Pujiang & 97.74 & 101.17 & 46.90 \\
\hline (21) & Dawei, Xiaojin & 94.87 & 132.09 & 83.66 \\
\hline (22) & Lengqi, Luding & 109.49 & 120.29 & 46.77 \\
\hline (23) & Qingping, Jinzhu & 824.12 & 802.71 & 622.91 \\
\hline$(24)$ & Zoushishan, Pi County & 120.51 & 142.20 & 99.12 \\
\hline (25) & Daxing, Pujiang & 195.81 & 190.33 & 58.99 \\
\hline (26) & Youzha, Qionglai & 173.78 & 199.85 & 55.09 \\
\hline (27) & Bajiao, Shifang & 556.17 & 581.59 & 633.07 \\
\hline (28) & Anhong, Songpan & 186.54 & 131.63 & 89.28 \\
\hline (29) & Wolong, Wenchuan & 957.70 & 652.85 & 948.10 \\
\hline$(30)$ & Lihua, Xinjin & 107.63 & 89.13 & 47.97 \\
\hline
\end{tabular}

TABLE 3: Distribution characteristics and distribution parameters of the bridge model.

\begin{tabular}{lcc}
\hline Parameter & Distribution pattern & Distribution parameter \\
\hline C55 concrete compressive strength & Normal distribution & $N(\mu=44, \sigma=4.5)$ \\
C35 concrete compressive strength & Normal distribution & $N(\mu=28, \sigma=4.3)$ \\
HRB335 rebar strength & Lognormal distribution & $L N(\mu=5.81, \sigma=0.08)$ \\
Bearing initial stiffness scaling factor & Uniform distribution & $U(0.5,1.5)$ \\
Concrete density & Uniform distribution & $U(2250,2750)$ \\
Secondary dead load scaling factor & Uniform distribution & $U(0.8,1.2)$ \\
Pile translational stiffness scaling factor & Uniform distribution & $U(0.5,1.5)$ \\
Pile rotational stiffness scaling factor & Uniform distribution & $U(0.5,1.5)$ \\
\hline
\end{tabular}

during construction process (such as raw materials, construction methods, environments, and construction workers), the material properties, component behavior, and load effect of actual bridge structure may face certain uncertainties, which thus will lead to uncertain seismic responses and capacity of bridge structures. Thus, uncertainties of these factors need to be considered in the seismic vulnerability analysis herein. According to the structural characteristics of a typical threespan continuous beam bridge on the Sichuan-Tibet railway, and based on Pan [22] and Tavares [23] et al.s findings and construction features in China, uncertainty parameters in the bridge model and their distribution were identified as shown in Table 3.

3.4. Determination of Bridge Structure Damage Indices. Before the generation of seismic fragility curves for the typical three-span continuous beam railway bridge, damage indices of each bridge component need to be determined. For 
TABLE 4: Damage states and parameters of piers.

\begin{tabular}{lcccccccc}
\hline \multirow{2}{*}{ Pier } & \multicolumn{2}{c}{ Slight damage } & \multicolumn{2}{c}{ Moderate damage } & \multicolumn{2}{c}{ Severe damage } & \multicolumn{2}{c}{ Complete destruction } \\
& Median & $\beta_{c}$ & Median & $\beta_{c}$ & Median & $\beta_{c}$ & Median & $\beta_{c}$ \\
\hline $1 \#$ & 1.00 & 0.246 & 1.23 & 0.246 & 1.61 & 0.472 & 4.61 & 0.472 \\
$2 \#$ & 1.00 & 0.246 & 1.24 & 0.246 & 1.64 & 0.472 & 4.64 & 0.472 \\
$3 \#$ & 1.00 & 0.246 & 1.23 & 0.246 & 1.64 & 0.472 & 4.64 & 0.472 \\
$4 \#$ & 1.00 & 0.246 & 1.17 & 0.246 & 1.64 & 0.472 & 4.64 & 0.472 \\
\hline
\end{tabular}

TABLE 5: Damage states and parameters of bearings.

\begin{tabular}{lcccccccc}
\hline \multirow{2}{*}{ Bearing type } & \multicolumn{2}{c}{ Slight damage } & \multicolumn{2}{c}{ Moderate damage } & \multicolumn{2}{c}{ Severe damage } & \multicolumn{2}{c}{ Complete destruction } \\
& Median & $\beta_{c}$ & Median & $\beta_{c}$ & Median & $\beta_{c}$ & Median & $\beta_{c}$ \\
\hline LQZ & $150 \mathrm{~mm}$ & 0.246 & $225 \mathrm{~mm}$ & 0.246 & $375 \mathrm{~mm}$ & 0.472 & $750 \mathrm{~mm}$ & 0.472 \\
KZQZ & $100 \mathrm{~mm}$ & 0.246 & $150 \mathrm{~mm}$ & 0.246 & $250 \mathrm{~mm}$ & 0.472 & $500 \mathrm{~mm}$ & 0.472 \\
\hline
\end{tabular}

Note. LQZ represented movable spherical steel bearing, whereas KZQZ represented movable hyperboloid spherical seismic isolated bearing.

piers, after comprehensively considering the characteristics of three-span continuous beam bridge and consulting literature findings $[3,6,24]$, curvature ductility ratio was finalized as the pier damage index. Specific method for damage index calculation is detailed in the literature [22]. The curvature ductility ratio, being less than 1.00 , implies elastic state and no damage for the piers, while other larger values mean more serious damage states. And the curvature ductility ratio, being larger than about 4.6, implies complete destruction for the common piers. As for bearings, since there is yet no descriptive research on quantifying the damage degree of spherical steel railway bearings or seismic isolated railway bearings, we thus identified the relations between damage degree of two bearing types and bearing displacements during study after consulting relevant literatures $[25,26]$. And those bearing displacements depend on the specific bearing devices with different displacement capacities. The displacement, being less than the design value, implies no damage for the bearings, while other larger values mean more serious damage states. The displacement of 5 times the design value is assumed as the complete destruction state for the bearings. Tables 4 and 5 show the median damage indices corresponding to various damage states of three-span continuous beam railway bridge piers and bearings. Meanwhile, seismic capacities of components were assumed to follow lognormal distribution, while the definition of uncertainties for each damage state was also needed. Nielson [1] used the coefficient of variation (COV) to describe such uncertainties, assuming that $\mathrm{COV}$ value was 0.246 for the former two damage states and was 0.472 for the latter two damage states. In this paper, the above assumption was employed to obtain the logarithmic standard deviations of bridge component ultimate states, as shown in Tables 4 and 5.

3.5. Probabilistic Seismic Demand Analysis. To generate fragility curves for various components of the typical threespan continuous beam bridge on the Sichuan-Tibet railway, study shall be conducted on the correlation between seismic demand of each component and ground motion intensity index, so as to further clarify their variation relations. Hence,
TABLE 6: Probabilistic seismic demand model of bridge components.

\begin{tabular}{lccc}
\hline \multirow{2}{*}{ Component name } & \multicolumn{2}{c}{ Regression parameter } & $\zeta$ \\
& $A$ & $B$ & \\
\hline 1\# pier bottom section & 1.509 & -0.1089 & 0.38 \\
2\# pier bottom section & 1.331 & -1.0447 & 0.47 \\
3\# pier bottom section & 1.514 & -0.1177 & 0.43 \\
4\# pier bottom section & 1.361 & -1.446 & 0.48 \\
1\# pier bearing & 0.865 & 0.859 & 0.35 \\
3\# pier bearing & 0.79 & 0.661 & 0.37 \\
4\# pier bearing & 0.967 & 0.922 & 0.40 \\
\hline
\end{tabular}

probabilistic seismic demand analysis on each component was required, with the analytical procedure shown as follows.

Firstly, based on the 90 actually measured ground motion records of Wenchuan earthquake selected in Section 3.3.1, and with the employment of IDA analysis [27], 90 ground motions were amplitude modulated to 10 different PGA intensities from 0.1 to $1.0 \mathrm{~g}$ at a step size of $0.1 \mathrm{~g}$ to form sample database consisting of a total of 900 ground motions.

To reduce sampling error, Latin hypercube sampling [28] was used to sample uncertainty parameters in the model described in Section 3.3.2, so as to generate 900 typical bridge analysis samples.

Ground motion samples and bridge samples were paired one by one to generate ground motion-bridge analysis sample database. Then, OpenSEES was used to perform time-history analysis on the sample database and output the maximum dynamic response of dangerous bridge parts, including the curvature ductility ratio of pier bottom section $\mu_{\phi}$ and the maximum relative displacement of bearing $d$.

Probabilistic seismic demand model of each component was calculated by regression analysis on the maximum responses of components and ground motion intensity index.

Through probabilistic seismic demand analysis on the typical three-span continuous beam railway bridge according to the above procedure, demand model could be obtained for each component. Due to space limitations, only the calculation results of bridge components with spherical steel bearings could be given herein (Table 6). 


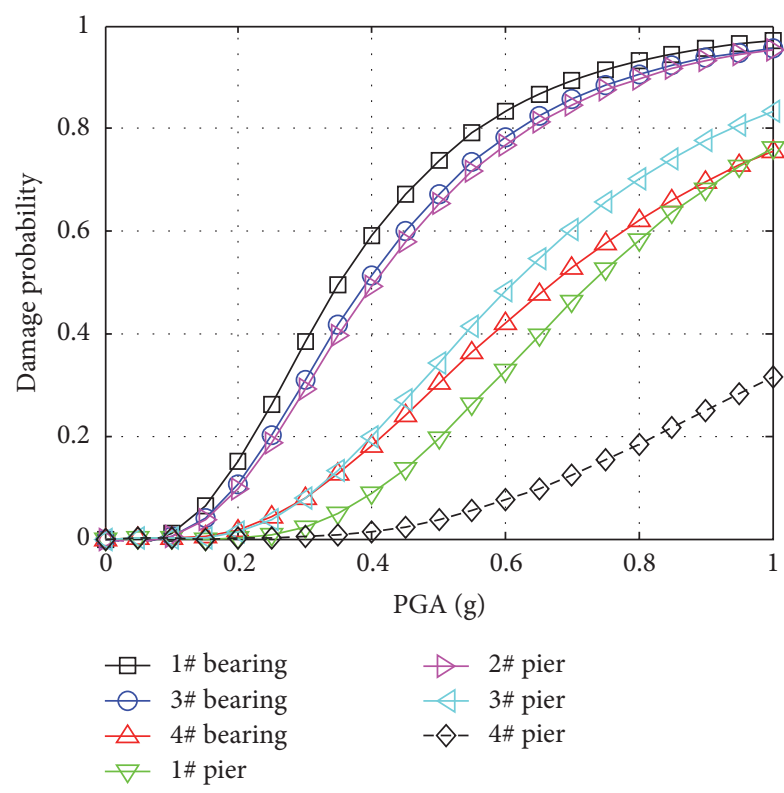

(a) Slight damage

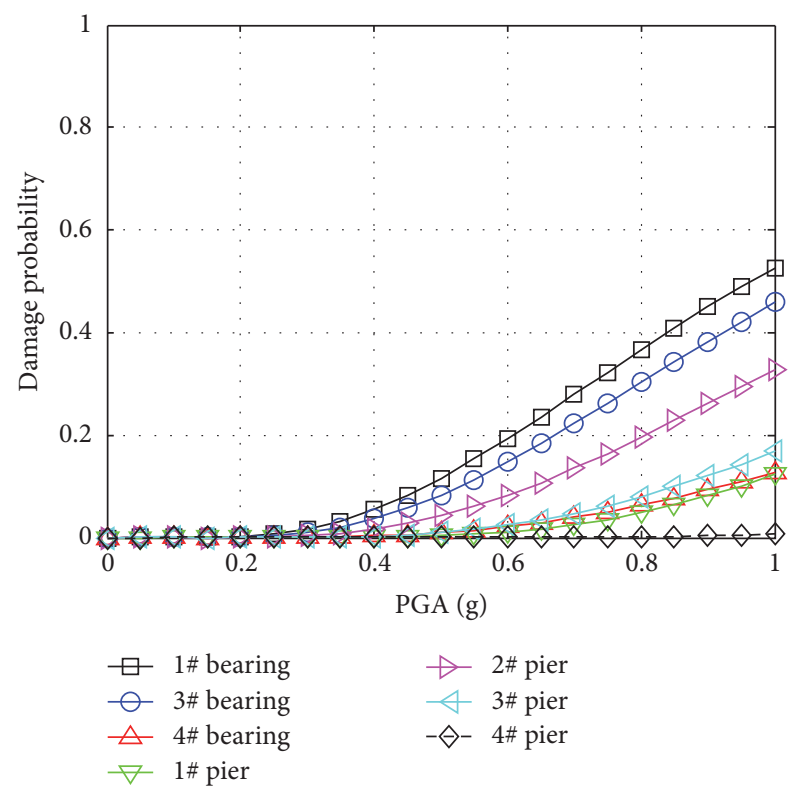

(c) Severe damage

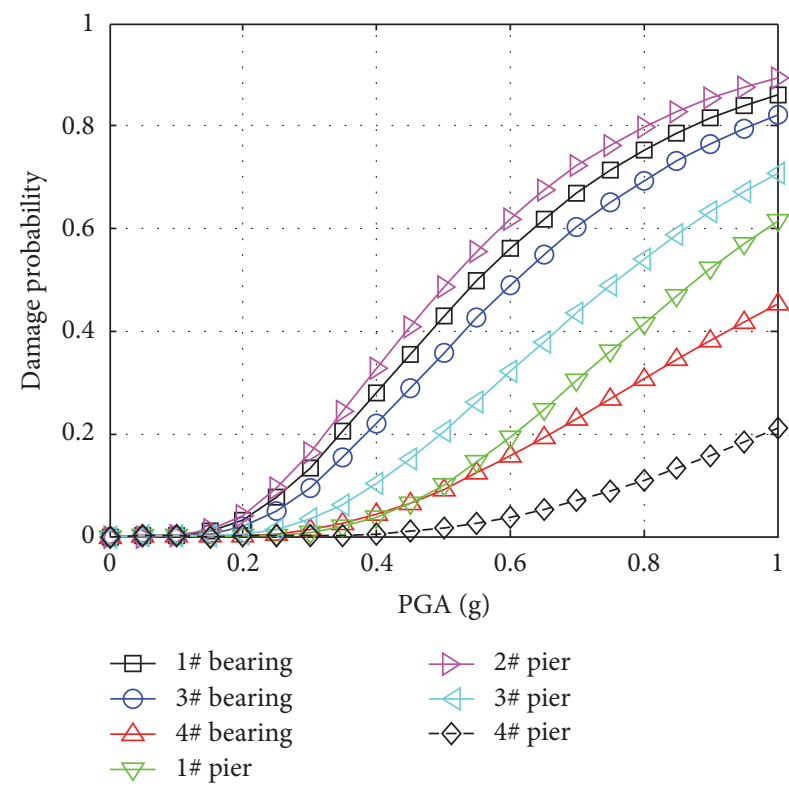

(b) Moderate damage

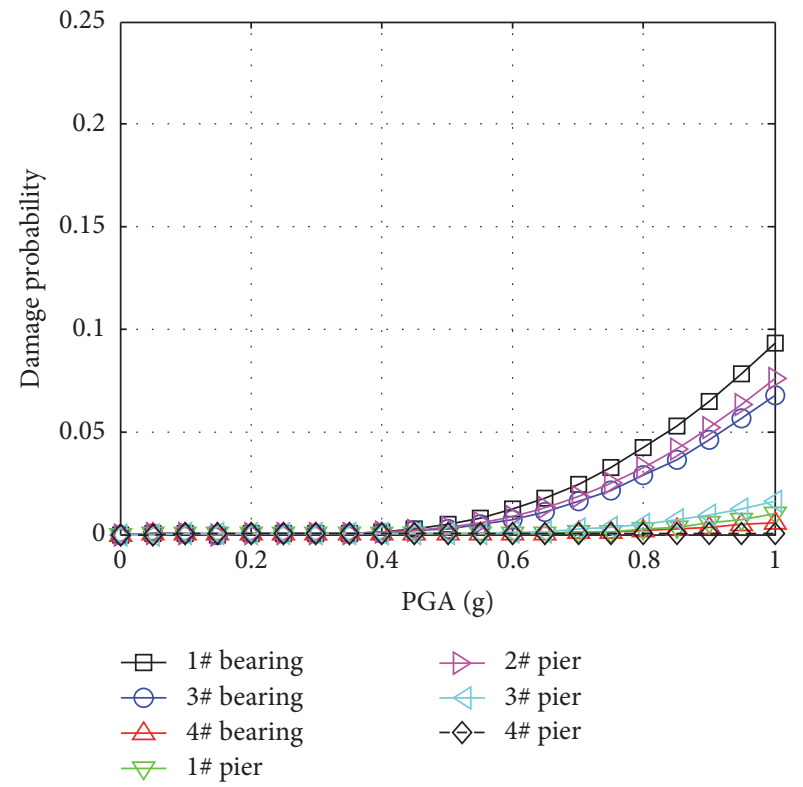

(d) Complete destruction

FIGURE 4: Vulnerability curves of different components with spherical steel bearing.

3.6. Seismic Vulnerability Analysis. Based on the above probabilistic seismic demand analysis results of bridge components, as well as median damage indices of various components, fragility curves were constructed for each component using formula (6). Figures 4 and 5 illustrate the seismic vulnerability curves of piers and bearings corresponding to four damage states under two bearing types at PGA = 0-1.0 g. As can be seen, for the two different bearing types, the vulnerability curves for different components, however, shared the similar shapes. However, damage probabilities corresponding to different damage states had a slight difference. Vulnerability function parameters of components corresponding to slight and moderate damage states are shown in Table 7.

Analysis of Figure 4 showed that, for bridge piers, when PGA was $0.3 \mathrm{~g}$ (seismic intensity of 8 degrees), destruction probability of $2 \#$ pier (braking pier) was around $30 \%$ under slight damage state. For other non-braking piers, destruction probabilities were all lower than $10 \%$ in slight damage state. In comparison, the damage probabilities were almost zero in case of moderate, severe, and complete damage states. It can be indicated that the continuous beam bridge piers achieved a good seismic performance, and that braking pier was most susceptible to damage among all piers, with a 


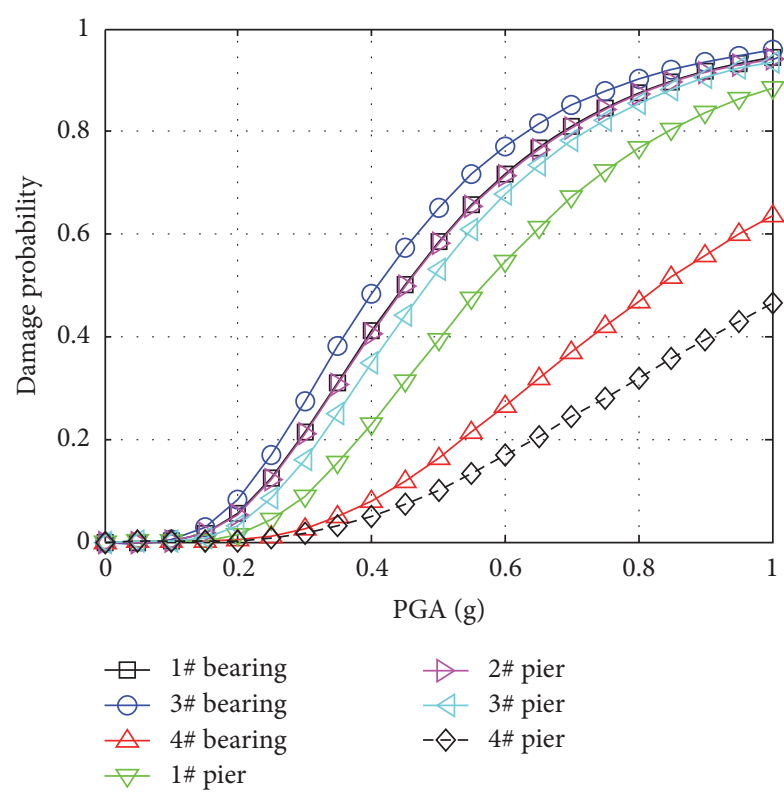

(a) Slight damage

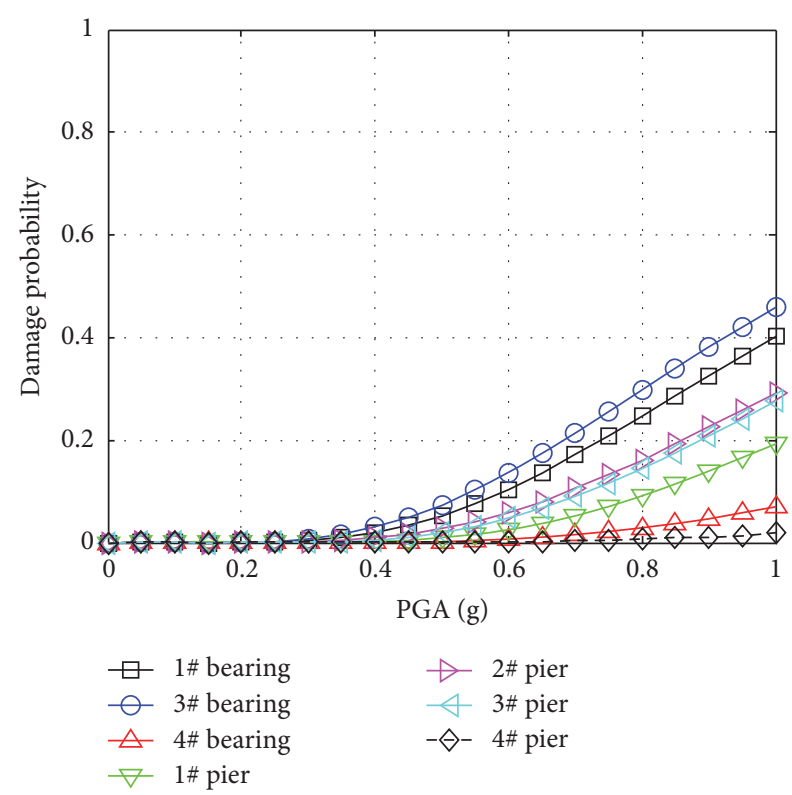

(c) Severe damage

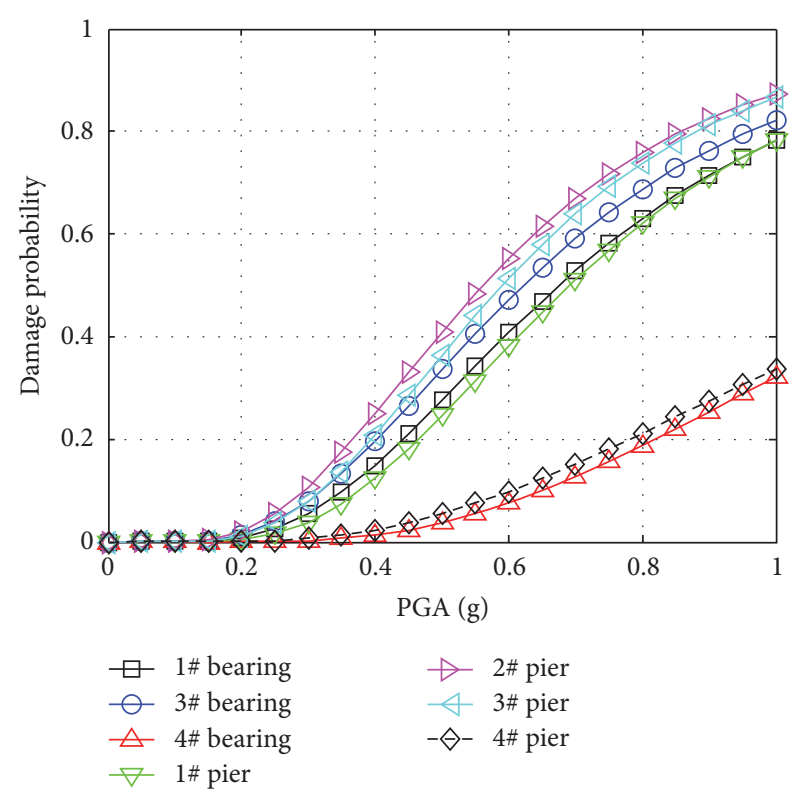

(b) Moderate damage

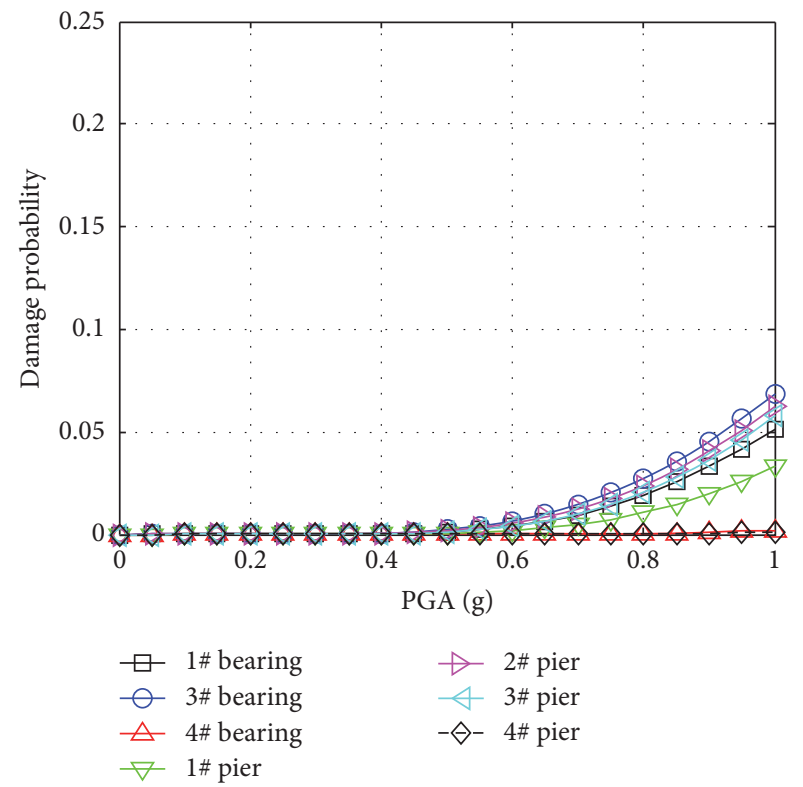

(d) Complete destruction

FIGURE 5: Vulnerability curves of different components with seismic isolated bearing.

destruction probability far higher than other piers under the same ground motion intensity. Thus, seismic isolation and reduction measured should be employed to reduce the seismic damage probability of 2\# pier (braking pier).

For bridge bearings, when PGA was $0.3 \mathrm{~g}$ (seismic intensity of 8 degrees), probability of slight damage was lower than $40 \%$; probability of moderate damage was also between 10 and $20 \%$, while damage probability was almost zero in severe and complete destruction states. It can be indicated that the spherical steel bearings of the continuous beam bridge were susceptible to slight and moderate damage. In addition, through the comparison of vulnerability between piers and corresponding bearings, it was shown that the bearings were more prone to damage.

Figure 5 showed that, for bridge piers, when PGA was $0.3 \mathrm{~g}$ (seismic intensity of 8 degrees), probability of slight damage was all lower than $21 \%$ and probability of moderate damage was lower than $11 \%$, while damage probability was almost zero in severe and complete damage states, which indicated that the continuous beam bridge piers had a good seismic performance. Moreover, through the comparison of seismic vulnerability between piers, it was shown that braking pier was most susceptible to damage among all piers. However, compared with the spherical steel bearings, seismic 
TABLE 7: The arguments to the vulnerability function of different components.

\begin{tabular}{|c|c|c|c|c|c|c|c|c|}
\hline \multirow[b]{3}{*}{ Component name } & \multicolumn{4}{|c|}{ With spherical steel bearing } & \multicolumn{4}{|c|}{ With seismic isolated bearing } \\
\hline & \multicolumn{2}{|c|}{ Slight damage } & \multicolumn{2}{|c|}{ Moderate damage } & \multicolumn{2}{|c|}{ Slight damage } & \multicolumn{2}{|c|}{ Moderate damage } \\
\hline & Median & $\begin{array}{c}\text { Logarithmic } \\
\text { standard } \\
\text { deviation } \beta\end{array}$ & Median & $\begin{array}{c}\text { Logarithmic } \\
\text { standard } \\
\text { deviation } \beta\end{array}$ & Median & $\begin{array}{c}\text { Logarithmic } \\
\text { standard } \\
\text { deviation } \beta\end{array}$ & Median & $\begin{array}{c}\text { Logarithmic } \\
\text { standard } \\
\text { deviation } \beta\end{array}$ \\
\hline $1 \#$ pier & 0.73 & 0.453 & 0.88 & 0.453 & 0.57 & 0.326 & 0.69 & 0.326 \\
\hline $2 \#$ pier & 0.40 & 0.530 & 0.51 & 0.530 & 0.46 & 0.424 & 0.56 & 0.424 \\
\hline 3\# pier & 0.61 & 0.495 & 0.76 & 0.495 & 0.48 & 0.351 & 0.59 & 0.351 \\
\hline 4\# pier & 1.32 & 0.539 & 1.48 & 0.539 & 1.04 & 0.420 & 1.32 & 0.420 \\
\hline 1\# pier bearing & 0.36 & 0.428 & 0.55 & 0.428 & 0.45 & 0.542 & 0.68 & 0.542 \\
\hline 3\# pier bearing & 0.39 & 0.444 & 0.61 & 0.444 & 0.41 & 0.613 & 0.62 & 0.613 \\
\hline 4\# pier bearing & 0.67 & 0.470 & 1.06 & 0.485 & 0.83 & 0.524 & 1.36 & 0.524 \\
\hline
\end{tabular}

vulnerability difference between piers became smaller after the use of seismic isolated bearings. It was mainly because, after the use of the seismic isolated bearings, horizontal bearing capacities of bearings were all $20 \%$ of vertical bearing capacities, which varied greatly from the horizontal bearing capacity of spherical steel bearings [29]. As a result, the piers were distributed more uniformly, along with fewer differences concerning the damage probabilities of piers.

As for bridge bearings, there was small difference in damage probability between them. When PGA was $0.3 \mathrm{~g}$ (seismic intensity of 8 degrees), probability of slight damage was lower than $32 \%$; while probability of moderate damage was lower than $15 \%$, thus indicating that the seismic isolated bearings of the continuous beam bridge were susceptible to slight damage. In addition, it can be found through the comparison of vulnerability between piers and corresponding bearings that the bearings were more prone to damage. This finding was similar to the calculation results under spherical steel bearing conditions.

To further understand the seismic vulnerability of each component, the median exceedance probability ground motion intensity index was used to describe the component vulnerability. That is, in case of certain state of damage, components with smaller median PGA were more prone to seismic damage and failure.

Figures 6 and 7 show the histograms for comparison of median exceedance probability PGA between various components in slight and moderate damage states with two bearing types.

Figure 6 shows that under spherical steel bearing conditions for slight damage state, median PGA values were the smallest for $1 \#$ and $3 \#$ bearings, namely, 0.36 and $0.39 \mathrm{~g}$, respectively. It indicated that $1 \#$ and $3 \#$ bearings were most susceptible to slight damage, followed by $2 \#$ braking pier prone to slight damage. For moderate damage state, 2\# pier (braking pier) had the smallest median PGA, with a value of $0.51 \mathrm{~g}$, thus indicating that $2 \#$ pier was most susceptible to moderate damage, followed by $1 \#$ pier bearing, 3\# pier bearing, 3\# pier, $1 \#$ pier, and $4 \#$ pier. Besides, vulnerability ranking results somewhat differed between slight and moderate damage states.

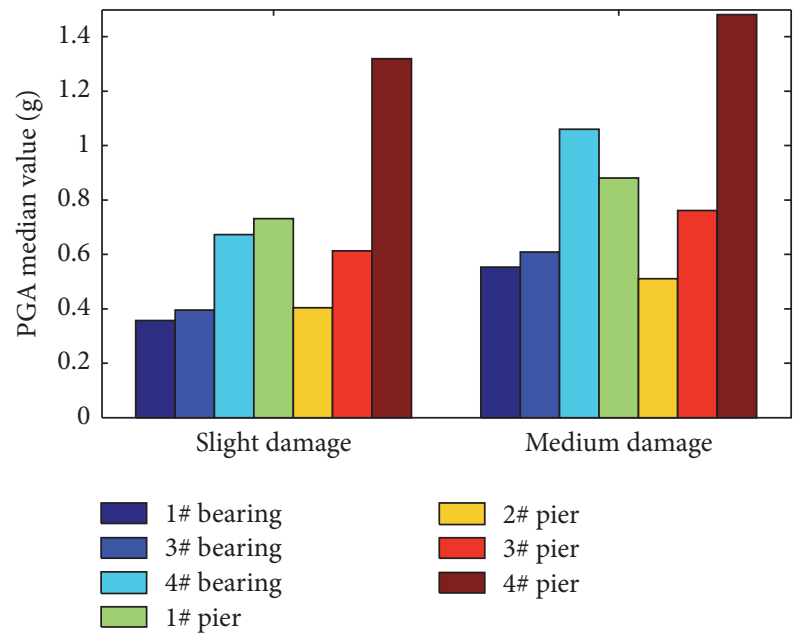

FIGURE 6: Median value of PGA of different components with spherical steel bearing.

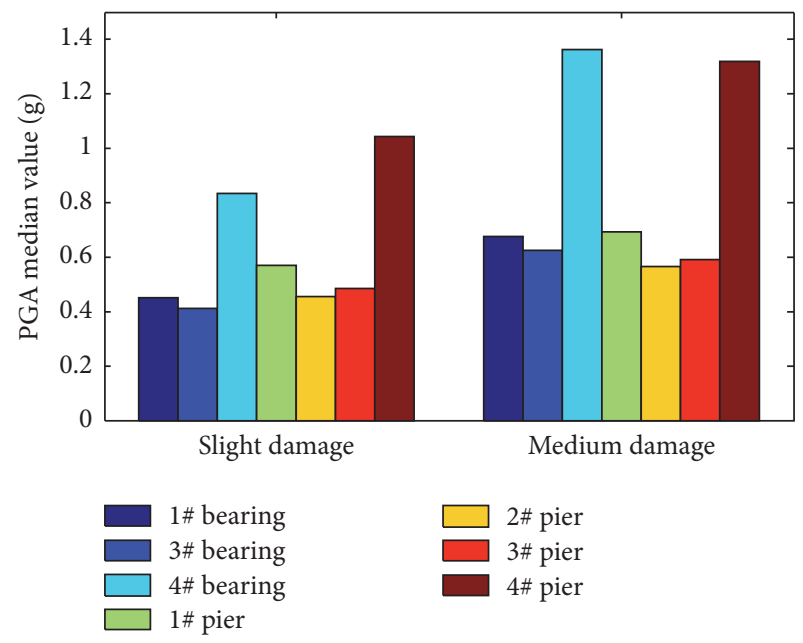

Figure 7: Median value of PGA of different components with seismic isolated bearing.

Figure 7 shows that, under seismic isolated bearing conditions for slight damage state, median PGA ranged between 
0.41 and $0.83 \mathrm{~g}$ for various components. With median PGA values being 0.41 and $0.45 \mathrm{~g}$, respectively, $3 \#$ and $1 \#$ pier bearings were most susceptible to slight damage, followed by 2\# pier, 3\# pier, 1\# pier, and 4\# pier bearing. For moderate damage state, $2 \#$ and $3 \#$ piers were most susceptible to damage and failure, followed by $3 \#$ pier bearing, 1\# pier bearing, 1\# pier, $4 \#$ pier bearing, and $4 \#$ pier, which somewhat differed from the results of slight damage state.

Based on the comparison between Figures 6 and 7, it was shown that, by the action of different bearing types, there was an obvious difference with the median PGA of components in various damage states. Therefore, it was necessary to conduct an in-depth study on the seismic vulnerability of the same components under two bearing types; besides, it was also necessary to investigate the differences between the two, so as to provide the basis for seismic design of typical three-span continuous beam railway bridges.

3.7. Comparative Analysis under Different Bearing Types. For studying the effects of two types of bearings on the seismic behavior of different components, variation trends relating to damage probability deviations of various vulnerable components with PGA under two bearing type conditions were presented (Figure 8 )

Figures 8(a)-8(c) show that, for various bearings, damage probability would experience a decrease under seismic isolated bearing condition. In slight, moderate, and severe damage states, damage probability deviations corresponding to $1 \#$ and $3 \#$ bearings all presented the first increase at first, followed by the decrease trend with an increase of PGA. For 4\# pier bearing, its damage probability deviations in four corresponding damage states all increased with an increase of PGA.

For 3\# bearing, its maximum damage deviations in various damage states would not exceed $5 \%$, which meant that the damage probabilities of the $3 \#$ pier bearing in various damage states with the presence of seismic isolated bearing were not significantly lower than that with spherical steel bearing. That is, there was no qualitative difference in the vulnerability results of the component under two different bearing types of conditions. This was mainly due to the large difference in the displacement control parameter between the two bearing types (Table 5). With possible improvement of displacement control parameter of the seismic isolated bearing (e.g., adjusting to displacement parameter $150 \mathrm{~mm}$ to be the same as the spherical steel bearing), there would be qualitative difference in the reduction rate of damage probability of the seismic isolated bearing.

For $1 \#$ and 4\# side pier bearings, their maximum damage probability deviations in slight, moderate, and severe damage states all exceeded $10 \%$. In terms of $1 \#$ side bearing, the maximum damage probability deviation in severe damage state would also exceed $10 \%$. It indicated that, for side bearings (1\# and 4\# bearings), the seismic isolated bearing had excellent seismic reduction and isolation effects despite the different displacement control parameters between the spherical steel bearing and the seismic isolated one.

Figures $8(\mathrm{~d})-8(\mathrm{~g})$ show that, for $1 \#, 3 \#$, and $4 \#$ piers, their damage probability deviations were negative, while, for 2\# pier (braking pier), its damage deviations in various damage states were all positive. It indicated that, after the use of seismic isolated bearing, damage probabilities of $2 \#$ pier (braking pier) for corresponding damage states all experienced a decrease by seismic action, while, for the remaining piers (1\#, 3\#, and 4\# piers), damage probabilities somewhat experienced an increase in various damage states. This was mainly because the horizontal ultimate bearing capacity increased by $15 \%$ for $1 \#, 3 \#$, and $4 \#$ movable pier bearings after the use of the seismic isolated bearing compared with the use of spherical steel bearing. When it comes to 2\# pier fixed bearing, on the other hand, its horizontal ultimate bearing capacity decreased by $10 \%$ after the use of the seismic isolated bearing compared with the application of spherical steel bearing. Thus, under ground motion, damage energy borne by $1 \#, 3 \#$, and $4 \#$ piers (non-braking piers) would increase, and, correspondingly, their damage probability would also increase $[30,31]$. At that time, due to the lowered damage energy borne by $2 \#$ pier, the damage probability under ground motion, therefore, would decrease for $2 \#$ pier.

For 2\# pier (braking pier), its seismic damage probability could be reduced by around $13 \%$ at maximum in slight to moderate damage states after the employment of the seismic isolated bearing, which occurred at a PGA of around $0.4 \mathrm{~g}$. In severe and complete damage states, the seismic isolated bearing could reduce the damage probability by $7 \%$ and $2 \%$ at maximum, respectively, which occurred at $1.0 \mathrm{~g}$. For 1\#, 3\#, and 4\# piers (non-braking piers), moreover, their damage probabilities in slight to moderate damage states all increased after the use of seismic isolated bearing, with a maximum increase of around 20\%. However, as shown in Figure 5, after the application of seismic isolated bearing, 2\# pier (braking pier) was still the most susceptible to damage [3234]. Nevertheless, seismic vulnerabilities of the other three piers were closer to the braking pier, thus proving that, after the use of the seismic isolated bearing, four piers could more uniformly withstand the earthquake damage energy.

\section{Conclusions}

Based on IDA analysis and taking into account uncertainties in the ground motion and bridge structure parameters, seismic vulnerability analysis is performed on the structure of a typical three-span continuous beam bridge on the Sichuan-Tibet railway. Moreover, comparative studies have been conducted on the effects of two types of bearings (spherical steel bearing and seismic isolated bearing) on the vulnerability of dangerous bridge components. The main conclusions are drawn as follows:

Piers of the typical three-span continuous beam bridge on the Sichuan-Tibet railway have a good seismic performance. In case of the earthquake with PGA less than $0.3 \mathrm{~g}$ (seismic intensity of 8 degrees), slight damage probability of $2 \#$ pier (braking pier) was lower than $30 \%$. When it comes to other non-braking piers, however, the probability was lower than $10 \%$. With good seismic performance, severe damage or complete destruction is almost unlikely for piers.

Through the comparative study on the vulnerability of piers and their corresponding bearings, it was found that 


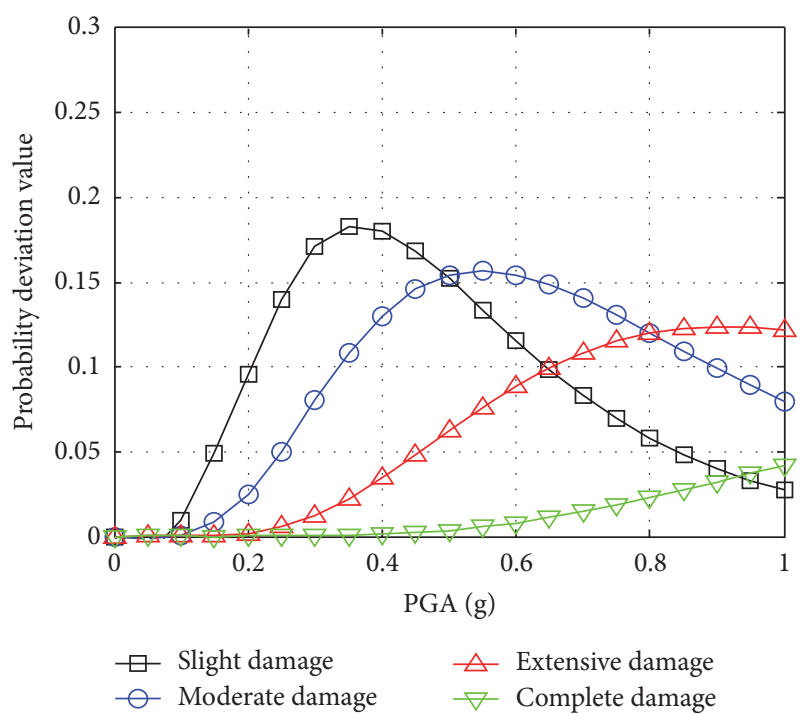

(a) 1\# pier bearing

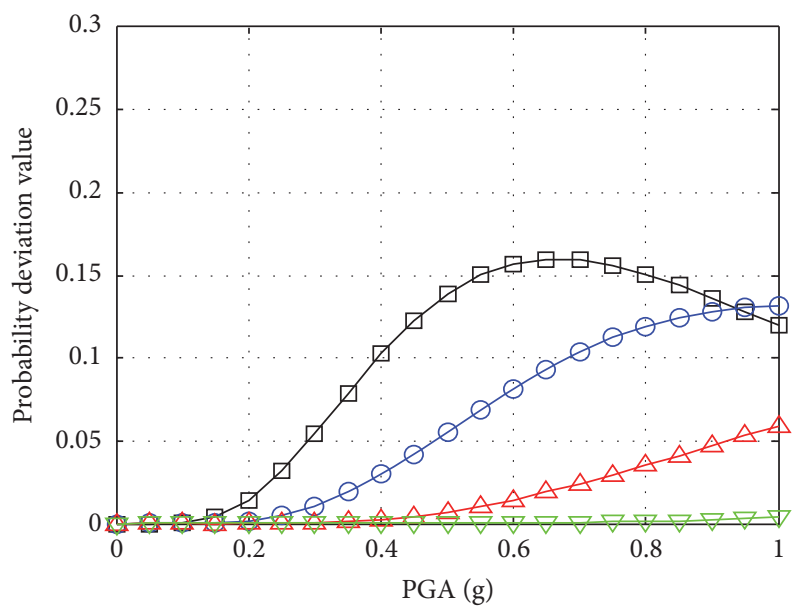

$\begin{array}{ll}\square \text { Slight damage } & \triangle \text { Extensive damage } \\ \ominus \text { Moderate damage } & \nabla \text { Complete damage }\end{array}$

(c) 4\# pier bearing

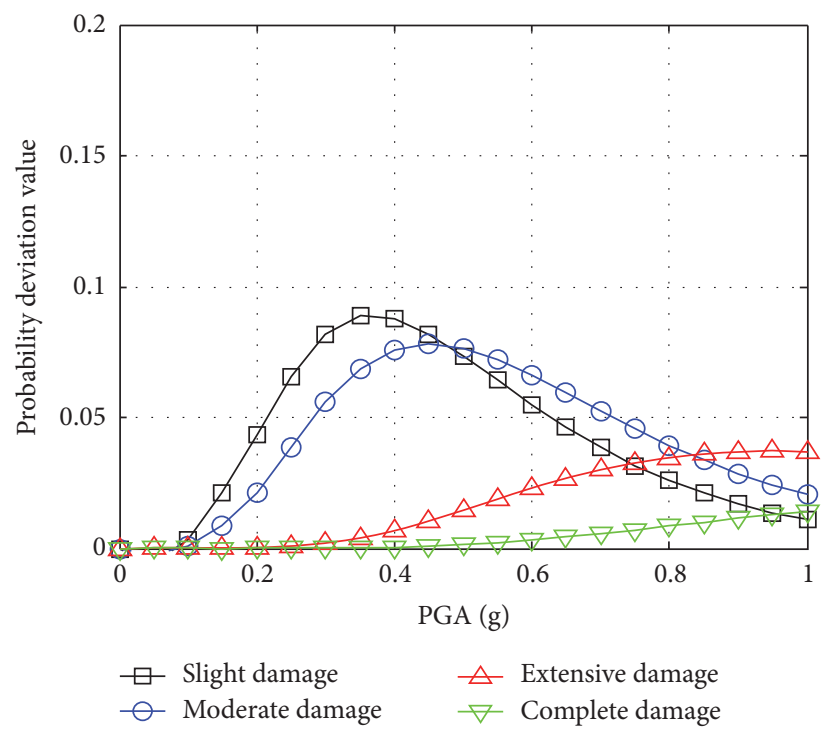

(e) 2\# pier

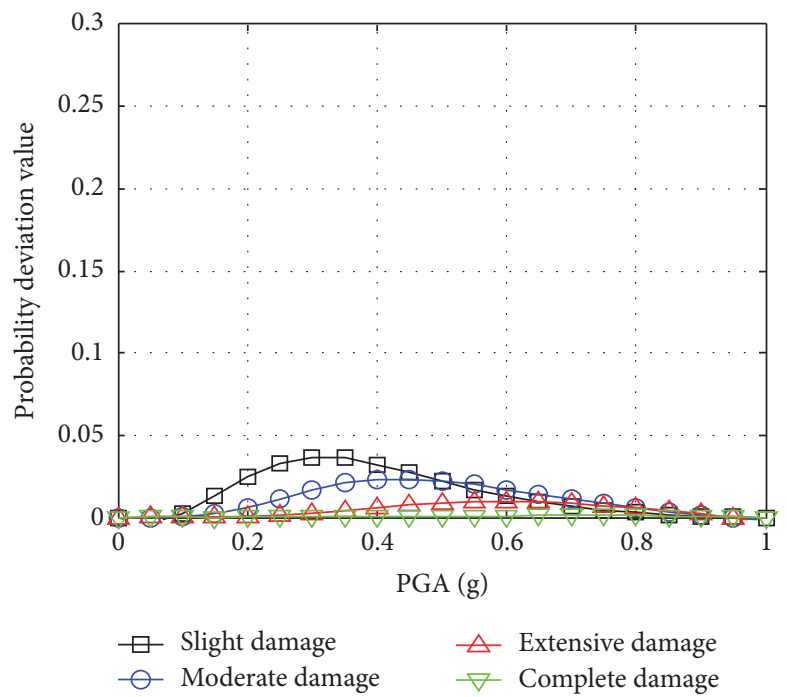

(b) 3\# pier bearing

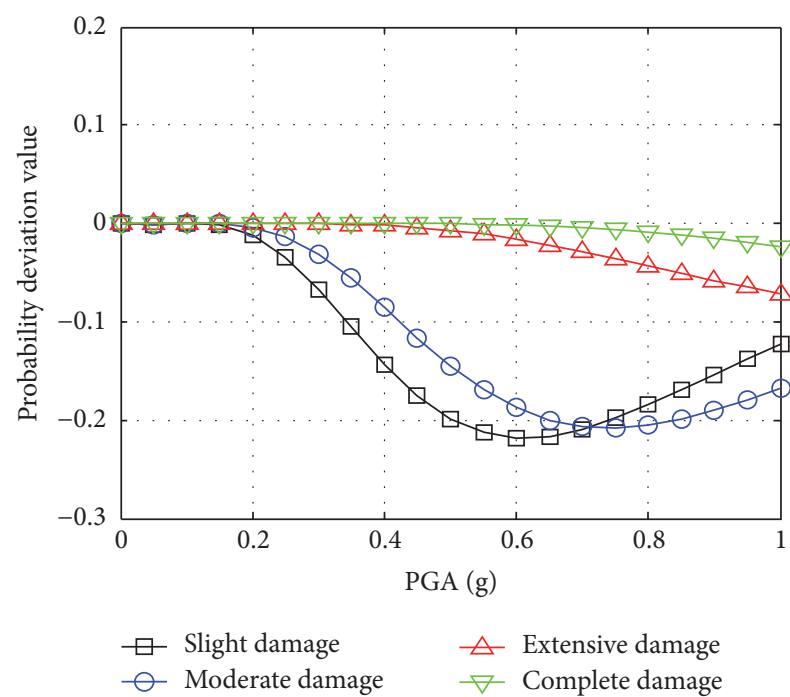

(d) 1\# pier

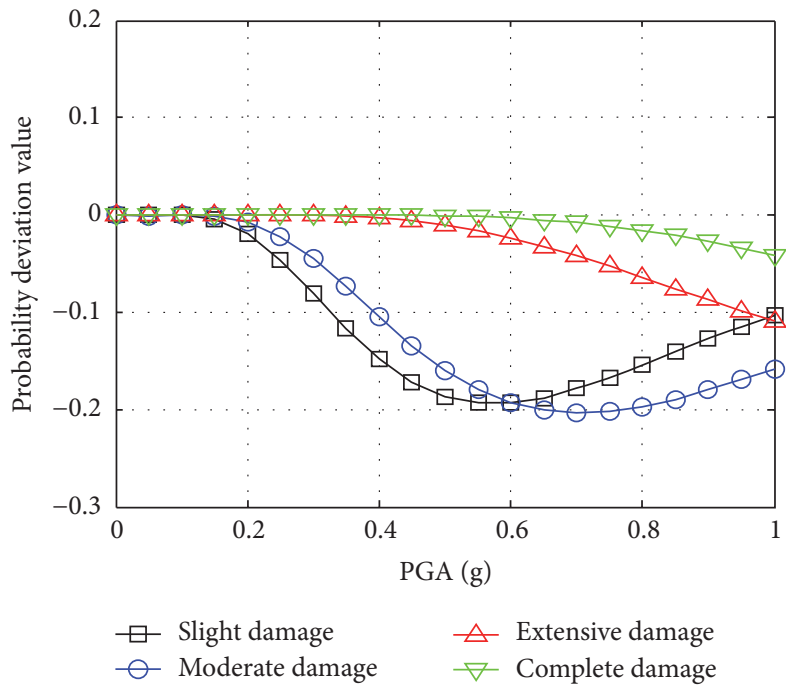

(f) 3\# pier

Figure 8: Continued. 


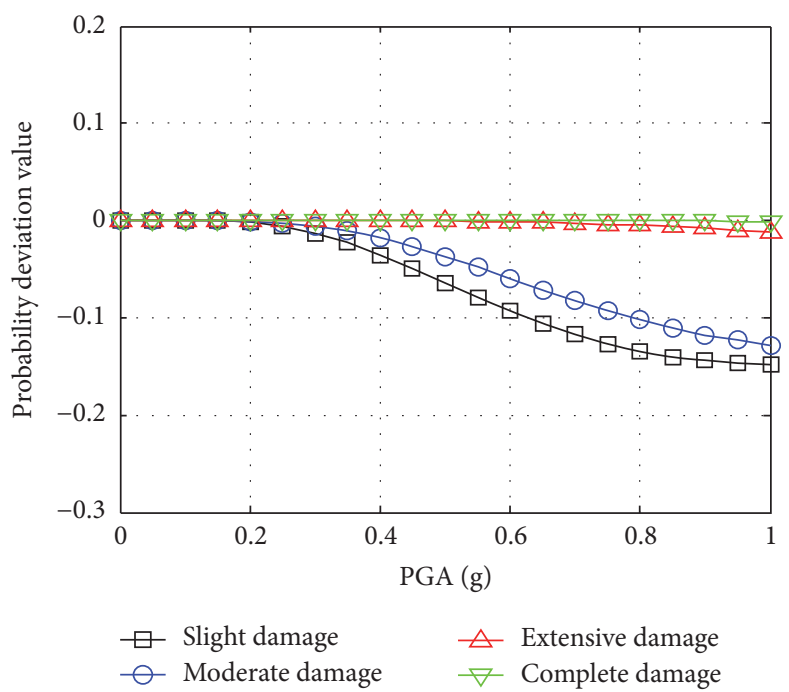

(g) 4\# pier

FIGURE 8: Deviation plots of damage probability of different components under the prerequisite of two different kinds of bearing with and without seismic isolation. Note. The figures above were deviation plots obtained by subtracting damage probabilities of components under spherical steel bearing condition from those under seismic isolated bearing condition.

bearings are more susceptible to damage than piers, thus suggesting that bearings are seismic damage prone components in the continuous beam railway bridges.

With the use of spherical steel bearing, vulnerability of 2\# pier (braking pier) is significantly higher than the other three piers. After the application of seismic isolated bearing, vulnerability gained a reduction for the 2\# pier (braking pier), while there would be an increase for the other three piers. However, the vulnerability of braking pier is still the greatest. Besides, at this time, fragility curves of the other three piers are relatively close to the braking pier, which indicates that, with the use of seismic isolated bearing, four piers are able to withstand the earthquake damage energy more uniformly.

Based on the analysis of deviation plots of damage probability of bridge pier bearings, the damage probability deviations are more distinct for side pier bearings. However, 3 \# central pier bearing has very small damage probability deviations with the seismic isolated bearing. Therefore, the adjustment of displacement control parameter for the seismic isolated bearings is recommended, in order to further reduce the seismic vulnerability of each bearing.

\section{Conflicts of Interest}

The authors declare that there are no conflicts of interest regarding the publication of this paper.

\section{Acknowledgments}

This research is jointly supported by the National Natural Science Foundation of China (51338004, 51778635, 51308549, 51378504, and 51478475), the Natural Science Foundations of Hunan Province (2015JJ3159), the Special Fund of Strategic Leader in Central South University (2016CSU001), the Innovation-Driven Plan in Central South University (2015CX006), the Experimental Foundations of the New Railway from Chengdu to Lanzhou (CLRQT-2015-010), and the Graduate Innovative Project in Central South University (2016zzts399). The support is greatly appreciated.

\section{References}

[1] B. G. Nielson, Analytical Fragility Curves for Highway Bridge in Moderate Seismic Zones, Georgia Institute of Technology, Atlanta, 2005.

[2] T. Rossetto and A. Elnashai, "A new analytical procedure for the derivation of displacement-based vulnerability curves for populations of RC structures," Engineering Structures, vol. 27, no. 3, pp. 397-409, 2005.

[3] H. Hwang, J. B. Liu, and Y. Chiu, "Seismic Fragility Analysis of Highway Bridges, Referenzmodellierung," 2001.

[4] B. G. Nielson and R. DesRoches, "Seismic fragility methodology for highway bridges using a component level approach," Earthquake Engineering \& Structural Dynamics, vol. 36, no. 6, pp. 823-839, 2007.

[5] D. F. Gianmarco and R. Giannini, "An efficient approach for seismic fragility assessment with application to old reinforced concrete bridges," Journal of Earthquake Engineering, vol. 14, pp. 231-251, 2010.

[6] E. Choi, R. DesRoches, and B. Nielson, "Seismic fragility of typical bridges in moderate seismic zones," Engineering Structures, vol. 26, no. 2, pp. 187-199, 2004.

[7] Y. Wang, Seismic Response Analysis and Vulnerability of Isolated Railway Bridge, Zhejiang University, Zhejiang, China, 2013.

[8] C. D. Zhou and J. J. Wang, "Seismic vulnerability analysis of railway bridges," Journal of Beijing Jiaotong University, vol. 38, no. 4, pp. 101-106, 2014.

[9] J. Feng, Seismic Vulnerability Analysis of Bridge Structures, Southwest Jiaotong University, Chengdu, 2009. 
[10] J. H. Zhang, Seismic Vulnerability Analysis of Regular Bridge Piers Based on Numerical Simulation, Tongji University, Shanghai, China, 2006.

[11] C. A. Cornell, F. Jalayer, R. O. Hamburger, and D. A. Foutch, "Probabilistic basis for 2000 SAC federal emergency management agency steel moment frame guidelines," Journal of Structural Engineering, vol. 128, no. 4, pp. 526-533, 2002.

[12] B. Wei, P. Wang, B. Yan, L. Jiang, and X. He, "Parameter optimization of damper-friction isolation systems using concave friction distribution," Journal of Vibroengineering, vol. 18, no. 3 , pp. 1668-1682, 2016.

[13] J. E. Padgett and R. DesRoches, "Methodology for the development of analytical fragility curves for retrofitted bridges," Earthquake Engineering and Structural Dynamics, vol. 37, no. 8, pp. 1157-1174, 2008.

[14] R. P. Kennedy and M. K. Ravindra, "Seismic fragilities for nuclear power plant studies," Nuclear Engineering Design, vol. no. 79, pp. 47-68, 1984.

[15] B. Wei, "Study of the Applicability of Modal Pushover Analysis on Irregular Continuous Bridges," Structural Engineering International, vol. 21, no. 2, pp. 233-237, 2011.

[16] A. Neuenhofer and F. C. Filippou, "Evaluation of Nonlinear Frame Finite-Element Models," Journal of Structural Engineering, vol. 123, no. 7, pp. 958-966, 1997.

[17] D. C. Kent and R. Park, "Flexural members with confined concrete," Journal of the Structural Division, vol. 97, no. 7, pp. 1969-1990, 1971.

[18] M. Menegotto and P. E. Pinto, Method of analysis for cyclically loaded RC plane frames including changes in geometry and nonelastic behavior of elements under combined normal force and bending, IABSE, Lisbon, Portugal, 1973.

[19] B. Yan, G.-L. Dai, and N. Hu, "Recent development of design and construction of short span high-speed railway bridges in China," Engineering Structures, vol. 100, pp. 707-717, 2015.

[20] CARS Railway Engineering Research Institute, Railway Design Institute, TB/T 2331-2004 Pot Bearings for Railway Bridge, China Railway Publishing House, Beijing, China, 2004.

[21] Ministry of Railways of the PRC, TB 10002.5-2005 Specifications for Design of Railway Bridge and Culvert Foundations, China Railway Publishing House, Beijing, China, 2005.

[22] Y. Pan, A. K. Agrawal, and M. Ghosn, "Seismic Fragility of Continuous Steel Highway Bridges in New York State," Journal of Bridge Engineering, vol. 12, no. 6, pp. 689-699, 2007.

[23] D. H. Tavares, J. E. Padgett, and P. Paultre, "Fragility curves of typical as-built highway bridges in eastern Canada," Engineering Structures, vol. 40, pp. 107-118, 2012.

[24] Japan Railway Technical Research Institute, "Standards and Interpretation for Design of Railway Structures - Seismic Design,” Tech. Rep., Maruzen, Japan, 2000.

[25] B. Wei, P. Wang, X. He, and L. Jiang, "The impact of the convex friction distribution on the seismic response of a spring-friction isolation system," KSCE Journal of Civil Engineering.

[26] Transport Industry Standards of the PRC, Pot Bearings for Highway Bridges (JT/T 391-2009), Ministry of Transport of the PRC, Beijing, China, 2009.

[27] D. Vamvatsikos and C. A. Cornell, "Incremental dynamic analysis," Earthquake Engineering Structural Dynamics, vol. 31, no. 3, pp. 491-514, 2002.

[28] A. Olsson, G. Sandberg, and O. Dahlblom, "On Latin hypercube sampling for structural reliability analysis," Structural Safety, vol. 25, no. 1, pp. 47-68, 2003.
[29] B. Wei, T. Yang, L. Jiang, and X. He, "Effects of friction-based fixed bearings on the seismic vulnerability of a high-speed railway continuous bridge," Advances in Structural Engineering, p. $136943321772689,2017$.

[30] B. Wei, P. Wang, W. Liu, M. Yang, and L. Jiang, "The impact of the concave distribution of rolling friction coefficient on the seismic isolation performance of a spring-rolling system," International Journal of Non-Linear Mechanics, vol. 83, pp. 6577, 2016.

[31] B. Wei, P. Wang, T. Yang, G. Dai, L. Jiang, and Y. Wen, "Effects of friction variability on isolation performance of rolling-spring systems," Journal of Central South University, vol. 23, no. 1, pp. 233-239, 2016.

[32] X. He, T. Wu, Y. Zou, Y. F. Chen, H. Guo, and Z. Yu, "Recent developments of high-speed railway bridges in China," Structure and Infrastructure Engineering, vol. 13, no. 12, pp. 1584-1595, 2017.

[33] X. Kang, L. Jiang, Y. Bai, and C. C. Caprani, "Seismic damage evaluation of high-speed railway bridge components under different intensities of earthquake excitations," Engineering Structures, vol. 152, pp. 116-128, 2017.

[34] N. Hu, G. Dai, B. Yan, and K. Liu, "Recent development of design and construction of medium and long span high-speed railway bridges in China," Engineering Structures, vol. 74, pp. 233-241, 2014. 


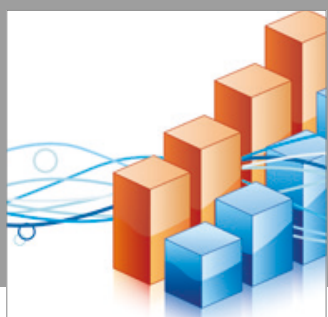

Advances in

Operations Research

vatersals

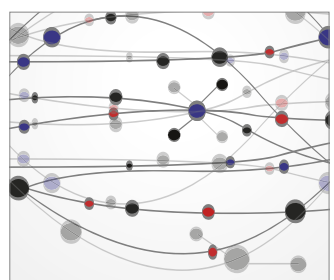

\section{The Scientific} World Journal
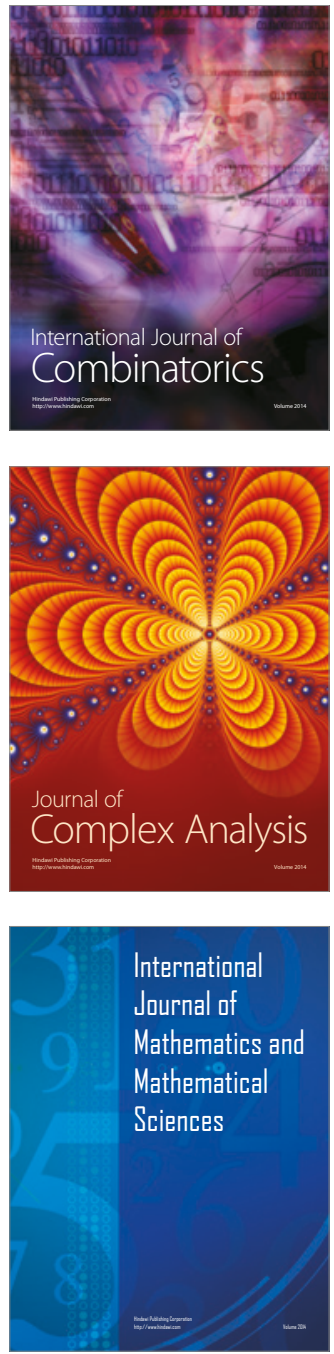
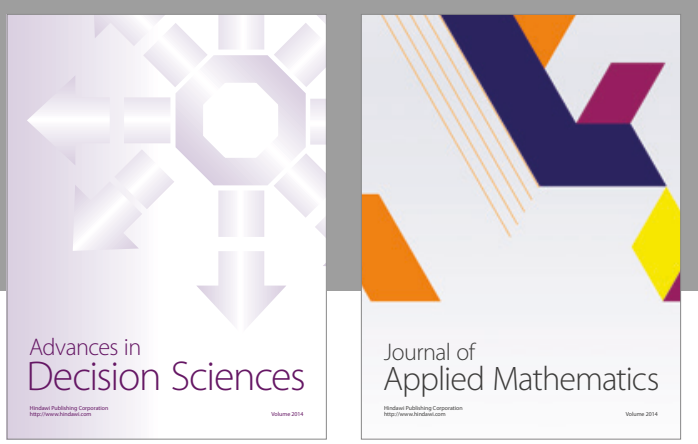

Algebra

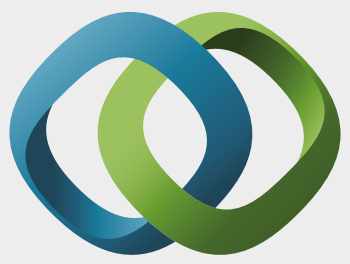

\section{Hindawi}

Submit your manuscripts at

https://www.hindawi.com
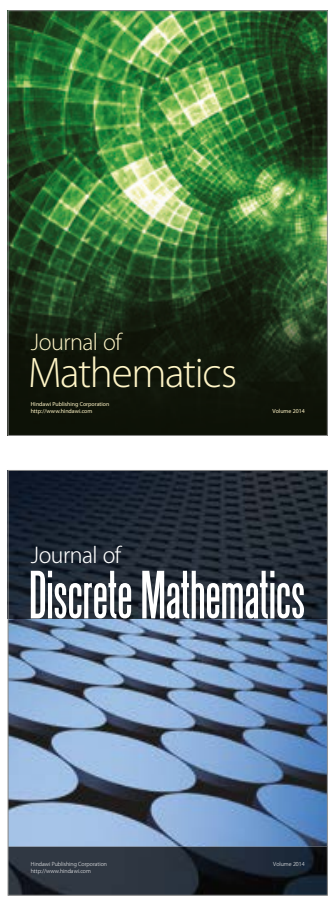

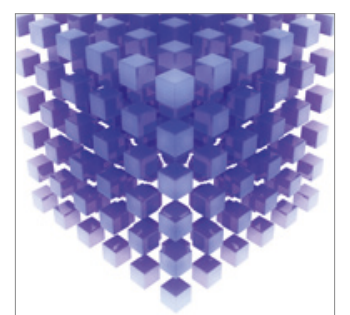

Mathematical Problems in Engineering
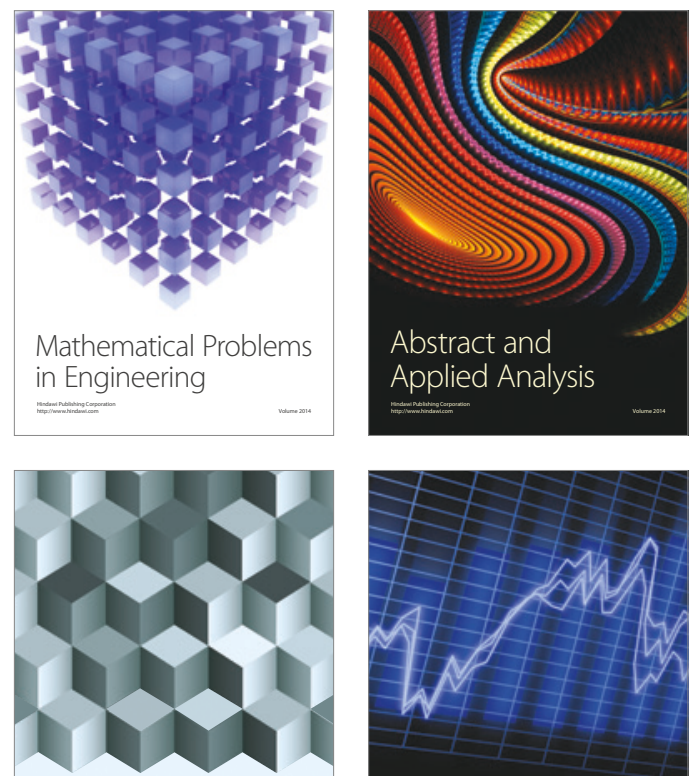

Journal of

Function Spaces

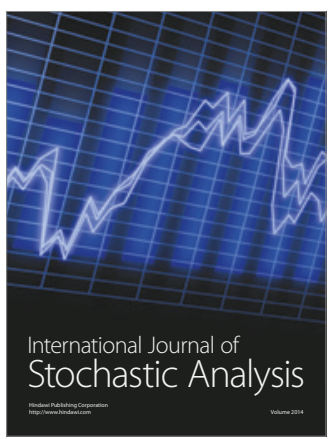

Probability and Statistics
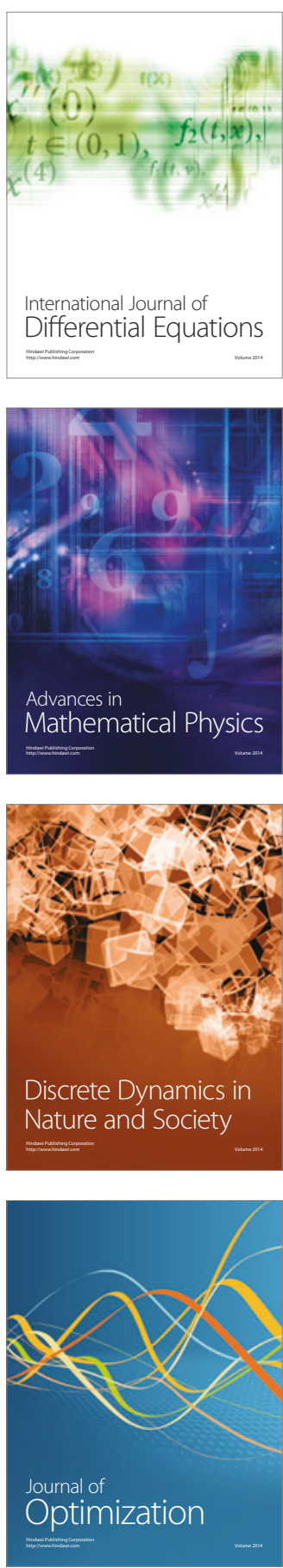